\title{
Development of a novel sports medicine rotation for emergency medicine residents
}

This article was published in the following Dove Press journal:

Advances in Medical Education and Practice

21 April 2016

Number of times this article has been viewed

\author{
Anna L Waterbrook' \\ T Gail Pritchard ${ }^{2}$ \\ Allison D Lane' \\ Lisa R Stoneking' \\ Bryna Koch ${ }^{2}$ \\ Robert McAtee' \\ Kristi H Grall' \\ Alice A Min' \\ Jessica Prior ${ }^{1}$ \\ Isaac Farrell' \\ Holly G McNulty' \\ Uwe Stolz'
}

'Department of Emergency Medicine, ${ }^{2}$ Office of Medical Student Education, The University of Arizona, Tucson, AZ, USA
Correspondence: Anna LWaterbrook Department of Emergency Medicine, The University of Arizona, PO Box 245057, Tucson, AZ 85724-5057, USA

Tel +I 5206266312

Fax +I 5206262480

Email awaterbrook@aemrc.arizona.edu
Abstract: Musculoskeletal complaints are the most common reason for patients to visit a physician, yet competency in musculoskeletal medicine is invariably reported as a deficiency in medical education in the USA. Sports medicine clinical rotations improve both medical students' and residents' musculoskeletal knowledge. Despite the importance of this knowledge, a standardized sports medicine curriculum in emergency medicine (EM) does not exist. Hence, we developed a novel sports medicine rotation for EM residents to improve their musculoskeletal educational experience and to improve their knowledge in musculoskeletal medicine by teaching the evaluation and management of many common musculoskeletal disorders and injuries that are encountered in the emergency department. The University of Arizona has two distinct EM residency programs, South Campus (SC) and University Campus (UC). The UC curriculum includes a traditional 4-week orthopedic rotation, which consistently rated poorly on evaluations by residents. Therefore, with the initiation of a new EM residency at SC, we replaced the standard orthopedic rotation with a novel sports medicine rotation for EM interns. This rotation includes attendance at sports medicine clinics with primary care and orthopedic sports medicine physicians, involvement in sport event coverage, assigned reading materials, didactic experiences, and an on-call schedule to assist with reductions in the emergency department. We analyzed postrotation surveys completed by residents, postrotation evaluations of the residents completed by primary care sports medicine faculty and orthopedic chief residents, as well as the total number of dislocation reductions performed by each graduating resident at both programs over the last 5 years. While all residents in both programs exceeded the ten dislocation reductions required for graduation, residents on the sports medicine rotation had a statistically significant higher rate of satisfaction of their educational experience when compared to the traditional orthopedics rotation. All SC residents successfully completed their sports medicine rotation, had completed postrotation evaluations by attending physicians, and had no duty hour violations while on sports medicine. In our experience, a sports medicine rotation is an effective alternative to the traditional orthopedics rotation for EM residents.

Keywords: musculoskeletal medicine, musculoskeletal education, medical education, orthopedics

\section{Introduction}

Musculoskeletal complaints are the most common reason for patients to visit a physician and account for 92.1 million cases annually. ${ }^{1}$ These disorders account for almost $30 \%$ of visits to primary care physicians ${ }^{1}$ and are the most common class of complaints presenting to the emergency department (ED), representing $20 \%$ of visits. ${ }^{2,3}$ While not all musculoskeletal disorders are emergent, they have a huge societal impact and may lead to significant disability. Therefore, physicians in many specialties, including 
emergency medicine (EM), need to identify and manage these conditions appropriately.

Despite the prevalence of musculoskeletal disorders, competency in musculoskeletal medicine is invariably reported as a deficiency in medical education in the USA. ${ }^{4-19}$ This shortcoming is well documented through studies at both the undergraduate and graduate medical education levels. . $^{5,11-17,20}$ These studies have shown that medical students and residents lack confidence in their mastery of musculoskeletal medicine $e^{5,7,12,15}$ and are deficient in musculoskeletal physical examination knowledge and skills. ${ }^{5,15-17}$ This deficiency is noted even among orthopedic surgery residents ${ }^{16}$ and program directors of internal medicine departments. ${ }^{6}$ Given this lack of confidence and deficiency of knowledge and skills at all levels of medical education, it is no surprise that a survey of practicing primary care physicians revealed that more than half of them did not feel they had adequate training in musculoskeletal medicine. ${ }^{1}$ Additionally, 56\% reported that their only training in musculoskeletal medicine was in medical school, not residency. ${ }^{1}$ Most importantly, even when this training does occur, it is usually brief and not always directly relevant to the common disorders seen in the outpatient setting. ${ }^{18}$

Sports medicine clinical rotations improve both medical students' and residents' musculoskeletal knowledge. ${ }^{11,15,21-23}$ In two separate studies of medical students, the only factor leading to a significant increase in musculoskeletal knowledge and confidence among the 4th-year medical students was participation in a musculoskeletal clinical elective. ${ }^{11,15,21}$ There is also a correlation between increased objective structured clinical examination scores designed to test medical knowledge and clinical judgment (not surgical skills) with increased sports medicine experience ${ }^{22}$ in orthopedic residents. Additionally, in a study of family medicine residents, researchers found significant improvement in residents' basic musculoskeletal medical knowledge with the introduction of a sports medicine clinical rotation and dedicated curriculum. ${ }^{23}$ Family medicine residents in programs accredited by the Accreditation Council for Graduate Medical Education (ACGME) are currently required to spend at least 200 hours dedicated to the care of musculoskeletal problems, including a structured sports medicine experience. ${ }^{24}$ We have identified only study assessing the knowledge of musculoskeletal medicine among EM providers. ${ }^{19}$ This study "identified significant deficiencies among these physicians at various stages of their careers at an academic medical center as measured by a validated examination of musculoskeletal knowledge with only $61 \%$ obtaining a passing score." Along with previ- ously described data, the existing literature suggests there is a knowledge and training gap in EM as well.

Most EM residency programs include a 1-month orthopedic surgery rotation during the intern year. These rotations are common, but not mandatory. Anecdotally, this rotation often involves what residents describe as "scut-work", including preoperative preparation of patients, postoperative checks, and discharging of patients. This translates to the perception of minimal teaching because orthopedic residents and attendings are often in the operating room, leaving interns to do floor work. The rotation usually focuses on the surgical management of musculoskeletal disease, rather than on the less severe but more common musculoskeletal pathology. In particular, the musculoskeletal physical examination is underemphasized in this setting. Despite the fact that the evaluation of musculoskeletal complaints is an essential skill for the emergency physician, there is no standardized sports medicine curriculum in most EM residencies.

The University of Arizona (UA) has two distinct EM residency programs, South Campus (SC) and University Campus (UC). The UC curriculum includes a traditional 4-week orthopedic rotation, which has consistently rated poorly on evaluations by residents. For this reason, with the initiation of a new EM residency at SC in 2010, we replaced the standard orthopedic rotation with a novel sports medicine rotation for EM interns. To our knowledge, this is the first rotation of its kind in an EM program.

\section{Methods}

\section{Educational objectives}

The goals and objectives for the sports medicine rotation at SC (Table 1) were developed based upon the Model Curriculum and Guidelines for Curriculum Development for Emergency Medicine Residency Training created by the Society for Academic Emergency Medicine and the Council of Emergency Medicine Residency Directors. ${ }^{25}$ This model curriculum was designed to be used as a resource and guide in developing curriculum for EM residency programs. This document includes a comprehensive list of specific goals and objectives for core content material, including orthopedics and prioritizing content items, to indicate the depth and breadth of knowledge required of a specialist in EM.

The primary objectives of our sports medicine rotation are to: 1) improve EM residents' musculoskeletal educational experience, and 2) improve their knowledge in musculoskeletal medicine by teaching the evaluation and management of many common musculoskeletal disorders and injuries encountered in the ED. 
Table I Goals and objectives for the sports medicine rotation

Identify anatomy, mechanism of injury, presentations, complications, and management and prognosis of common musculoskeletal injuries.

Demonstrate ability to correctly perform a history and physical examination in patients with musculoskeletal disorders, with an emphasis on the shoulder, elbow, wrist/hand, hip, knee, ankle/foot, neck, and back. Develop an appropriate differential diagnosis for musculoskeletal disorders. Interpret radiographs correctly in patients with orthopedic injuries.

Define standard orthopedic nomenclature.

Demonstrate ability to apply orthopedic devices, including compressive dressings, splints, and immobilizers.

Demonstrate skill in performance of the following procedures: fracture/ dislocation immobilization, and reduction, arthrocentesis.

Outline appropriate aftercare and rehabilitation of sports medicine and orthopedic injuries, including concussions.

Recognize, assess, and manage the rare but life-threatening sports and orthopedic injuries.

\section{Curricular design}

These objectives are achieved through a 4-week rotation with sports medicine during the first year of residency and through participation in the management of ED patients during the 3 years of the residency. While residents are on their 4-week sports medicine rotation, they are assigned to attend daily sports medicine and orthopedic clinics affiliated with the UA, including Campus Health Services. In these settings, residents are supervised by either a primary care sports medicine (PCSM) or orthopedic attending physician; Table 2 shows a sample SM rotation schedule. Residents are responsible for evaluating and managing patients who present to clinic with a variety of musculoskeletal complaints under the direct supervision of their attending physician. Clinical experience occasionally includes time in an athletic training room with a certified athletic trainer, depending upon availability. Residents are also encouraged to attend sporting events covered by the PCSM faculty and fellows as available and appropriate.

In addition, all residents are assigned textbook readings covering orthopedic emergencies, as well as selected current sports medicine articles, consensus statements, and guides to the musculoskeletal physical examination. Further, their rotation includes attending sports medicine didactics and journal club during the month of their rotation, usually occurring once per month.

Comparatively, the EM residency program at the UA UC includes a more traditional orthopedic rotation. This rotation involves the care of inpatient orthopedic patients, including preoperative preparation of patients, postoperative checks, discharging patients, and taking calls from the inpatient floors. The EM residents regularly provide consults on orthopedic issues for patients in the ED and on the inpatient floors. The majority of the UC EM residents' orthopedic rotation is spent in the hospital; however, they spend 1 day/week working in the sports medicine clinic with a PCSM attending. Finally, while the formal sports medicine or orthopedic 4-week rotation occurs during the first year of residency, it is expected that the residents will continue to use and further develop the skills they have learned throughout their residency seeing patients in the ED.

\section{Evaluation and feedback}

Multiple methods are utilized to evaluate both the sports medicine and orthopedic rotations, including faculty and chief resident assessment of resident performance, postrotation surveys by residents, and procedure log tracking. Residents on the sports medicine rotation are evaluated at the end of their rotation by PCSM faculty using a standard evaluation form based upon the six core competencies (patient care, medical knowledge, practice-based learning, interpersonal and communication skills, professionalism, and system-based practice). Residents on the orthopedic rotation are evaluated using a similar evaluation form based upon the six core competencies by orthopedic chief residents (postgraduate year 5) on service during the same block. Residents from both programs are also required to record dislocation reduction procedures performed in their procedure log. They are encouraged to log other procedures such as arthrocentesis; however, this is not a requirement. At the current time, no formal postrotation examinations are given at the conclusion of either the sports medicine or orthopedic rotations.

Table 2 A sample schedule for the primary care sports medicine rotation for South Campus EM residents

\begin{tabular}{|c|c|c|c|c|c|c|c|}
\hline Time & Sunday & Monday & Tuesday & Wednesday & Thursday & Friday & Saturday \\
\hline $8 \mathrm{am}-12$ pm & $\begin{array}{l}\text { Training room, event } \\
\text { coverage as available }\end{array}$ & AZISM or CHSM & $\begin{array}{l}\text { AZISM or } \\
\text { CHSM }\end{array}$ & $\begin{array}{l}\text { EM didactics } \\
\text { (7 am-noon) }\end{array}$ & $\begin{array}{l}\text { AZISM or } \\
\text { CHSM }\end{array}$ & AZISM or CHSM & $\begin{array}{l}\text { Training room, event } \\
\text { coverage as available }\end{array}$ \\
\hline I pm-5 pm & $\begin{array}{l}\text { Training room, event } \\
\text { coverage as available }\end{array}$ & AZISM or CHSM & $\begin{array}{l}\text { AZISM or } \\
\text { CHSM }\end{array}$ & $\begin{array}{l}\text { Orthopedic Hand } \\
\text { Surgery Clinic }\end{array}$ & $\begin{array}{l}\text { AZISM or } \\
\text { CHSM }\end{array}$ & AZISM or CHSM & $\begin{array}{l}\text { Training room, event } \\
\text { coverage as available }\end{array}$ \\
\hline 5 pm-7 pm & & $\begin{array}{l}\text { Sports medicine didactics } \\
\text { and journal club (third } \\
\text { Monday of each month) }\end{array}$ & & & & $\begin{array}{l}\text { Training room, } \\
\text { event coverage as } \\
\text { available (all days) }\end{array}$ & \\
\hline
\end{tabular}

Abbreviations: EM, emergency medicine; AZISM, Arizona Institute for Sports Medicine; CHSM, Campus Health Sports Medicine. 
Postrotation feedback by the residents on both rotations is obtained using anonymous surveys and, more informally, through direct feedback at the end-of-the-year resident retreat.

\section{Results}

We analyzed postrotation surveys from the sports medicine and orthopedic rotations completed by the residents, as well as postrotation evaluations completed by PCSM faculty and orthopedic chief residents for the first 5 years after the implementation of the sports medicine rotation. We also evaluated procedure logs for each graduating resident from both programs over the last 3 years. This included all five classes of interns who have completed the sports medicine rotation at $\mathrm{SC}$ and all three classes of SC residents who have graduated since the beginning of the $\mathrm{SC}$ residency program.

$\mathrm{SC}$ and $\mathrm{UC}$ residents are provided with the same postrotation survey form. This off-service postrotation survey form was developed internally by program directors and has been used for over 5 years to evaluate resident experiences on offservice rotations. Residents are asked to complete the survey on the New Innovations platform (New Innovations, Inc., Uniontown, OH, USA) at the end of each off-service rotation. They are sent automatic reminders from New Innovations as well as follow-up reminders by program coordinators when these are not completed. These surveys consist of eight questions that use a Likert-type scale of 1-3 to assess residents' satisfaction with their rotation $(\mathrm{Q} 1-7: 3=$ most of the time, 2= some of the time, $1=$ seldom. Q8: 3= very helpful, 2= helpful, $1=$ not helpful).

Data from individual evaluations were extracted from New Innovations into a comma-separated file, merged, and uploaded into the IBM SPSS Statistics 22 (IBM Corporation, Armonk, NY, USA) software for analysis. All analysis was conducted using SPSS except for the cross-tab analysis, which was conducted using R software (version 3.2.0; The R Foundation for Statistical Computing, Vienna, Austria). Data collected from the off-service postrotation survey are presented in Table 3 along with the mean score for each evaluation item for the sports medicine and orthopedic rotations. The mean scores for each evaluation item indicate that the sports medicine rotation was reviewed more favorably by residents than the orthopedic rotation. A $3 \times 2$ cross-tab analysis was conducted to assess the differences in mean scores between the rotations. The results of Fisher's exact test indicate that there was a statistically significant difference between rotations on survey items $4,5,6,7$, and 8 as measured by a Bonferonni-corrected $P$-value of $<0.0055$.
Table 3 Resident feedback on sports medicine rotation 20I0-20I5

\begin{tabular}{|c|c|c|c|}
\hline \multirow[t]{2}{*}{ Survey questions } & \multicolumn{2}{|c|}{$\begin{array}{l}\text { Mean score (SD); } 95 \% \mathrm{Cl} \text {; } \\
\text { and sample size }\end{array}$} & \multirow{2}{*}{$\begin{array}{l}\text { Cross-tab } \\
\text { results } \\
(P \text {-value })\end{array}$} \\
\hline & $\begin{array}{l}\text { Orthopedic } \\
\text { rotation }\end{array}$ & $\begin{array}{l}\text { Sports } \\
\text { medicine } \\
\text { rotation }\end{array}$ & \\
\hline $\begin{array}{l}\text { I. Workload was } \\
\text { adequate }\end{array}$ & $\begin{array}{l}2.63(0.58) ; \\
\mathrm{Cl} 2.50-2.75 \\
\text { and } n=80\end{array}$ & $\begin{array}{l}2.96(0.21) \\
\mathrm{Cl} 2.74-3.04 ; \\
\text { and } n=22\end{array}$ & 0.02749 \\
\hline $\begin{array}{l}\text { 2. Work complexity } \\
\text { was adequate for } \\
\text { level of training }\end{array}$ & $\begin{array}{l}2.45(0.65) ; \\
\mathrm{Cl} 2.3 \mathrm{I}-2.60 \text {; } \\
\text { and } n=80\end{array}$ & $\begin{array}{l}2.73(0.55) \\
\mathrm{Cl} 2.18-2.96 \\
\text { and } n=22\end{array}$ & 0.1639 \\
\hline $\begin{array}{l}\text { 3. Type and variety of } \\
\text { cases was good }\end{array}$ & $\begin{array}{l}2.58(0.65) \\
\mathrm{Cl} 2.43-2.72 \text {; } \\
\text { and } n=80\end{array}$ & $\begin{array}{l}2.86(0.35) \\
\mathrm{Cl} 2.5 \mathrm{I}-3.0 \mathrm{I} \\
\text { and } n=22\end{array}$ & 0.1769 \\
\hline $\begin{array}{l}\text { 4. Attending availability } \\
\text { for help and teaching } \\
\text { was good }\end{array}$ & $\begin{array}{l}\mathrm{I} .50(0.64) \\
\mathrm{Cl} \text { I.36-I.64; } \\
\text { and } n=80\end{array}$ & $\begin{array}{l}2.96(0.2 \mathrm{I}) \\
\mathrm{Cl} 2.74-3.04 \\
\text { and } \mathrm{n}=22\end{array}$ & 0.0004998 \\
\hline $\begin{array}{l}\text { 5. Attending teaching } \\
\text { quality was good }\end{array}$ & $\begin{array}{l}\text { I.97 (0.75); } \\
\text { Cl I.80-2.I4; } \\
\text { and } n=75\end{array}$ & $\begin{array}{l}3.00(0.00) ; \\
N / A ; \text { and } n=22\end{array}$ & 0.0004998 \\
\hline $\begin{array}{l}\text { 6. Call schedule was } \\
\text { satisfactory }\end{array}$ & $\begin{array}{l}2.27(0.8 \mathrm{I}) \\
\mathrm{Cl} 2.08-2.47 ; \\
\text { and } n=66\end{array}$ & $\begin{array}{l}3.00(0.00) ; \\
N / A ; \text { and } n=16\end{array}$ & 0.0009995 \\
\hline $\begin{array}{l}\text { 7. Organization of this } \\
\text { service was good }\end{array}$ & $\begin{array}{l}2.32(0.67) ; \\
\text { Cl } 2.17-2.46 \text {; } \\
\text { and } n=79\end{array}$ & $\begin{array}{l}2.96(0.21) \\
\mathrm{Cl} 2.74-3.04 \\
\text { and } n=22\end{array}$ & 0.0004998 \\
\hline $\begin{array}{l}\text { 8. Overall, this rotation } \\
\text { was helpful to my } \\
\text { education }\end{array}$ & $\begin{array}{l}2.19(0.62) \text {; } \\
\mathrm{Cl} 2.05-2.32 \text {; } \\
\text { and } n=80\end{array}$ & $\begin{array}{l}2.77(0.43) \\
\mathrm{Cl} 2.34-2.95 \\
\text { and } n=22\end{array}$ & 0.0004998 \\
\hline
\end{tabular}

Notes: Q I-7: $3=$ most of the time, $2=$ some of the time, I= seldom. Q8: $3=$ very helpful, $2=$ helpful, I= not helpful.

Abbreviations: $\mathrm{Cl}$, confidence interval; N/A, not applicable; $\mathrm{Q}$, question; SD, standard deviation.

SC residents completed 22/32 (69\%) postrotation surveys during the academic years 2010-2011, 2011-2012, 2012-2013, 2013-2014, and 2014-2015, and UC residents completed a total of $80 / 89(90 \%)$ postrotation surveys during the academic years 2010-2011, 2011-2012, 2012-2013, 2013-2014, and 2014-2015.

$\mathrm{SC}$ resident postrotation surveys contained very few resident comments; however, those included were uniformly positive. Many acknowledged individual attendings for their teaching during the rotation. One resident responded "all of them" when asked which PCSM attending faculty member contributed most to their education while on the sports medicine rotation. Another resident noted:

Really enjoyed working with the [sports medicine attendings in the sports medicine clinics]. [They] had the best patients for learning.

While UC residents spend most of their orthopedic month rotating with orthopedic surgery, they do spend 1 day/week with PCSM faculty in their sports medicine clinics. Comments 
from UC residents regarding their experience in the sports medicine clinic included:

More time in clinic with a focus on how to manage these patients in the ED would be more useful. In-house time is mostly spent doing floorwork, which has some benefit, but becomes less so after 4 weeks.

[Sports medicine clinic] was a very good experience.

In contrast, UC resident postrotation surveys regarding their inpatient orthopedic surgery experience contained comments such as:

This rotation was the epitome of scut-work as an intern.

$[\ldots]$ there was very little training in actual orthopedics.

This is a floor work rotation.

Very few reductions, lots of paperwork. The majority of this rotation, the ED resident is managing floor patients and doing consults, while the [orthopedic] residents are in the OR. Depending on schedule, it is unlikely that the ED resident will get to perform an appropriate amount of reductions for the number of hours worked.

There is hardly any formal teaching for us as residents.

Not a ton of interaction with attendings. Some were not even interested in acknowledging us.

Ten of the UC residents reported violating duty hour restrictions while on the orthopedic rotation over the last 5 years. Reasons given for these violations included working over 80 hours/week, working $>16$ hours during a single shift, as well as $<10$ hours off in between shifts. There were no reported duty hour violations during the sports medicine rotation.

Postrotation evaluations of the residents by PCSM faculty and orthopedic chief residents were also analyzed. Over the last 5 academic years, 32 SC residents have completed the sports medicine rotation and $89 \mathrm{UC}$ residents have completed the orthopedic rotation. All $32 \mathrm{SC}$ residents have completed postrotation sports medicine evaluations, while 57/89 (64\%) UC residents have completed postrotation orthopedic evaluations. Although all the postrotation evaluation forms used for both programs are currently based upon the six core competencies, the format and grading system used for SC residents has changed twice over the last 5 years to more accurately reflect ACGME requirements for evaluation of EM resident physicians. While a full quantitative assessment of these evaluations cannot be completed because of these changes, all SC residents and all UC residents with completed postrotation evaluations over the last 5 years have received satisfactory rotation evaluations from the PCSM faculty and orthopedic chief residents.

The number of dislocation reductions performed over the last 3 years for both SC and UC graduating seniors was calculated. These data were compiled from the graduating seniors' procedure logs documented in New Innovations from academic years 2012-2013, 2013-2014, and 2014-2015. Data on one of the SC graduates were excluded as an outlier because this resident had globally deficient documentation of all procedures.

All included residents in both programs either met or exceeded the EM ACGME required ten reductions needed for graduation. The mean number of reductions performed by the last three SC graduating classes $(n=21)$ on the sports medicine rotation was 19.3 (standard deviation [SD] 7.24, range: $10-35$ ) and 27.1 (SD 11.25, range: 10-57) for the last three UC graduating classes $(n=53)$ on the orthopedic rotation. An independent $t$-test analysis indicated that the mean difference in the number of reductions performed between programs is 0.029 (95\% confidence interval [CI]: 3.26-14.07), which is statistically significant.

\section{Discussion}

The introduction of a sports medicine rotation in the PGY-1 year of EM training has been very well received by our SC residents. SC residents on the sports medicine rotation had a statistically significant higher rate of satisfaction of their educational experience when compared to the traditional orthopedic rotation. The mean scores from residents on all eight questions evaluated on their postrotation surveys were higher at SC than at UC; five out of the eight questions showed a statistically significant difference, including questions related to the quality of attending teaching as well as overall value to their education. While resident satisfaction does not measure resident knowledge, residents' perception of the quality of their education while on sports medicine was consistently higher on sports medicine rotation than on orthopedic surgery rotation.

$\mathrm{SC}$ residents on the sports medicine rotation received significantly more attending feedback than UC residents on the orthopedic rotation. All SC residents successfully completed their sports medicine rotation and all had completed postrotation evaluations by PCSM faculty. Comparatively, only $64 \%$ of UC residents had completed postrotation evaluations by orthopedic chief residents, not orthopedic faculty. This was likely due to the minimal presence of attending availability and teaching as documented by UC residents on their postrotation satisfaction surveys. One resident commented: 
The few teaching moments I had with attendings were mostly indirect while they were teaching the [orthopedic] residents and not usually applicable to EM management and the attending physicians rarely acknowledged my presence and they did not teach $[\ldots]$.

The current EM graduation requirements include satisfactory completion of at least ten dislocation reductions. All of our SC EM residents, had on average, exceeded the number of reductions required, thus meeting or exceeding graduation requirements for dislocation reductions. However, because of a name change in the $\mathrm{SC}$ residency program, residents had to manually transfer each individual procedure from their procedure log of one institution to the other's New Innovations system. As a result, it is likely that some of the residents may have stopped documenting their procedures once they had recorded the number needed for graduation.

Currently, we have not implemented formal postrotation examinations for any of our off-service rotations at either program. In general, off-service postrotation examinations are not required and are infrequently used to determine successful rotation completion by residents. While EM residents take an in-service training examination yearly and are ultimately required to pass their American Board of Emergency Medicine certification examinations in order to become an American Board of Emergency Medicine board-certified physician, there is no dedicated orthopedic or sports medicine section of this examination. The orthopedic content is included in a large trauma section of this examination. To address this, we are currently working on a project to formally evaluate the core content musculoskeletal knowledge and physical examination skills of our current EM residents and faculty.

In 1993, the American Boards of Internal Medicine, Family Practice, Pediatrics, and Emergency Medicine jointly established certification in PCSM. ${ }^{26}$ While the American Academy of Family Physicians published core sports educational guidelines and has sports medicine as a required resident rotation, ${ }^{26}$ there is no published literature or guidelines on sports medicine training for EM residents. Most EM programs rely on inpatient orthopedic surgery rotations to meet the musculoskeletal education curriculum requirements. To our knowledge, there has never been any formal evaluation of whether or not an inpatient orthopedic rotation is truly meeting the needs of our EM residents. Theoretically, the main advantage of the orthopedics rotation is the ability to perform dislocation reductions. Whereas our UC EM residents do not differentiate the number of reductions they perform during their orthopedic rotation versus the number they perform in the $\mathrm{ED}$, anecdotally, they often get very few reductions on their orthopedic rotation. While the senior residents and attendings are in the operating room, the EM residents spend most of their daily tasks focused on the management of inpatient orthopedic surgical patients. There is very little time spent learning the basic clinical and cognitive skills needed to evaluate and treat most musculoskeletal complaints encountered in EM. Consistently, the orthopedic rotation is rated poorly by the residents on overall value to the residents' education compared to the sports medicine rotation. In addition, UC residents have had several duty hour violations during their orthopedic surgery rotation over the last 5 years; these violations included working over 80 hours/ week, working $>16$ hours during a single shift, as well as having $<10$ hours off in between shifts.

Our experience suggests that the implementation of a sports medicine rotation is a practical and useful alternative to the traditional orthopedic rotation for EM residents. SC residents' evaluation of the sports medicine experience has remained uniformly positive and has a statistically significant higher rate of satisfaction. All SC residents on average are able to meet or exceed graduation requirements as determined by the EM ACGME for the number of dislocation reductions, despite not rotating with orthopedic surgery; in addition, $\mathrm{SC}$ residents have not had any duty hour violations while on their sports medicine rotation over the last 5 years. Orthopedic rotations may not provide the optimal musculoskeletal curriculum for EM residents and may not be necessary to achieve competency in dislocation reductions as measured by the current residency graduation standards. Other programs may consider either adding a sports medicine component to their existing orthopedic rotation or completely replacing the orthopedic rotation with a sports medicine clinical experience. Future studies are needed and may focus on how to best achieve and evaluate clinical competency in musculoskeletal medicine for EM providers.

\section{Limitations}

There are several limitations to our study. This study was performed at a single institution and, therefore, may not be generalizable to other programs. Owing to the small SC resident class size, our sample size for SC residents is small. In addition, since the beginning of the $\mathrm{SC}$ residency, we have had turnover in our program coordinators as well as a transition in our New Innovations program for documentation of evaluations and procedures. This may have resulted in a decreased number of completed postrotation resident surveys 
and procedure logs. Finally, this study does not evaluate musculoskeletal knowledge or competency among the residents, but rather documents the successful implementation of an alternative to the traditional orthopedic inpatient rotation for EM residents at our institution.

\section{Acknowledgments}

The results of this study have been presented in an abstract form at the 2014 Western Society for Academic Emergency Medicine conference in Irvine, CA, USA, as well as at the 2014 National American Medical Society for Sports Medicine conference in New Orleans, LA, USA.

\section{Disclosure}

The authors report no conflicts of interest in this work.

\section{References}

1. Hing E, Cherry DK, Woodwell DA. National ambulatory medical care survey: 2004 summary. Adv Data. 2006;374:1-33.

2. Washington DL, Shekelle PG, Stevens CD. Deferred care for adults with musculoskeletal complaints. Eff Clin Pract. 2001;4:65-72.

3. De Lorenzo RA, Mayer D, Geehr EC. Analyzing clinical case distributions to improve an emergency medicine clerkship. Ann Emerg Med. 1990;19:746-751.

4. Booth A, Wise DI. General practice training in musculoskeletal disorders. Br J Gen Pract. 1990;40:390.

5. Freedman KB, Bernstein J. The adequacy of medical school education in musculoskeletal medicine. J Bone Joint Surg Am. 1998;80:1421-1427.

6. Freedman KB, Bernstein J. Educational deficiencies in musculoskeletal medicine. J Bone Joint Surg Am. 2002;84A(4):604-608.

7. Matzkin E, Smith EL, Freccero D, Richardson AB. Adequacy of education in musculoskeletal medicine. J Bone Joint Surg Am. 2005;87:310-314.

8. Bernstein J, Alonso DR, DiCaprio M, Friedlaender GE, Heckman JD, Ludmerer KM. Curricular reform in musculoskeletal medicine needs, opportunities, and solutions. Clin Orthop Relat Res. 2003; 415:302-308.

9. Bernstein J, King T, Lawry GV. Musculoskeletal medicine educational reform in the bone and joint decade. J Bone Joint Surg Am. 2007; 89:2308-2311.

10. Yeh AC, Franko O, Day CS. Impact of clinical electives and residency interest on medical students' education in musculoskeletal medicine. J Bone Joint Surg Am. 2008;90:307-315.

11. Schmale GA. More evidence of educational inadequacies in musculoskeletal medicine. Clin Orthop Relat Res. 2005;437:251-259.

12. Clawson DK, Jackson DW, Ostergaard DJ. It's past time to reform the musculoskeletal curriculum. Acad Med. 2001;76:709-710.
13. DiCaprio MR, Covey A, Bernstein J. Curricular requirements for musculoskeletal medicine in American medical schools. J Bone Joint Surg Am. 2003;85:565-567.

14. Skelley NW, Tanaka MJ, Skelley LM, LaPorte DM. Medical student musculoskeletal education: an institutional survey. J Bone Joint Surg Am. 2012;94:e146(1-7).

15. Day CS, Yeh AC, Franko O, Ramirez M, Krupat E. Musculoskeletal medicine: an assessment of the attitudes and knowledge of medical students at Harvard Medical School. Acad Med. 2007;82:452-457.

16. Beran MC, Awan H, Rowley D, Balch Samora J, Griesser MJ, Bishop JY. Assessment of musculoskeletal physical examination skills and attitudes of orthopaedic residents. J Bone Joint Surg Am. 2012;94:e36(1-8).

17. Bishop JY, Awan HM, Rowley DM, Nagel RW. Development and validation of a musculoskeletal physical examination decision-making test for medical students. J Surg Educ. 2013;70:451-460.

18. Akesson K, Dreinhöfer KE, Woolf AD. Improved education in musculoskeletal conditions is necessary for all doctors. Bull World Health Organ. 2003;81:677-683.

19. Comer GC, Liang E, Bishop JA. Lack of proficiency in musculoskeletal medicine among emergency medicine physicians. J Orthop Trauma. 2014;28:e85-7.

20. Association of American Medical Colleges [webpage on the Internet]. Contemporary Issues in Medicine: Musculoskeletal Medicine Education. Available from: https://members.aamc.org/eweb/DynamicPage. aspx?Action=Add\&ObjectKeyFrom=1 A83491A-9853-4C87-86A4F7D95601C2E2 \&WebCode $=$ PubDetailAdd $\&$ DoNotSave $=$ yes $\&$ ParentObject=CentralizedOrderEntry\&ParentDataObject=Invoice $\%$ 20Detail\&ivd_formkey $=69202792-63 \mathrm{~d} 7-4 \mathrm{ba2}-\mathrm{bf} 4 \mathrm{e}-\mathrm{a} 0 \mathrm{da} 41270555 \&$ ivd_prc_prd_key=669AF4A5-9359-45F2-814C-96EF3BF298D7. Accessed April 15, 2015.

21. DiGiovanni BF, Southgate RD, Mooney CJ, Chu JY, Lambert DR, O' Keefe RJ. Factors impacting musculoskeletal knowledge and clinical confidence in graduating medical students. J Bone Joint Surg Am. 2014;96:e185(1-7).

22. Dwyer T, Theodoropoulos JS, Herold J, et al. Assessing competence of orthopaedic residents: the reliability and validity of an objective structured clinical examination after a sports medicine rotation. J Bone Joint Surg Am. 2013;95:e177(1-9).

23. Watts SA, Zhang Z. Competency in musculoskeletal and sports medicine: evaluating a PGY-1 curriculum. Fam Med. 2011;43:659-663.

24. Accreditation Council for Graduate Medical Education [webpage on the Internet]. ACGME Program Requirements for Graduate Medical Education in Family Medicine. Available from: http://acgme.org/ acgmeweb/Portals/0/PFAssets/ProgramRequirements/120_family_ medicine_07012014.pdf. Accessed April 15, 2015.

25. Council of Emergency Medicine Residency Directors [webpage on the Internet]. Model Curriculum. Available from: http://www.cordem.org/ i4a/pages/index.cfm?pageID=3635. Accessed April 15, 2015.

26. Sweeney C, Davidson M, Melgar T, Patel D, Cucos D. The current status of sports medicine training in United States internal medicine residency programmes. Br J Sports Med. 2003;37:219-225.
Advances in Medical Education and Practice

\section{Publish your work in this journal}

Advances in Medical Education and Practice is an international, peerreviewed, open access journal that aims to present and publish research on Medical Education covering medical, dental, nursing and allied health care professional education. The journal covers undergraduate education, postgraduate training and continuing medical education

\section{Dovepress}

including emerging trends and innovative models linking education, research, and health care services. The manuscript management system is completely online and includes a very quick and fair peer-review system. Visit http://www.dovepress.com/testimonials.php to read real quotes from published authors. 